João Silvestre da Silva-Junior ${ }^{1}$

Flávia Souza e Silva de Almeida ${ }^{2}$

Márcio Prince Santiago ${ }^{3}$

Luiz Carlos Morrone ${ }^{2 *}$

\section{Caracterização do nexo técnico epidemiológico pela perícia médica previdenciária nos benefícios auxílio-doença}

\author{
Characterization of the technical epidemiological nexus in \\ social security sickness benefits by medical experts
}

\begin{abstract}
${ }^{1}$ Ministério da Previdência Social, Instituto Nacional do Seguro Social INSS. São Paulo, SP, Brasil.

${ }^{2}$ Faculdade de Ciências Médicas da Santa Casa de São Paulo, Departamento de Medicina Social. São Paulo, SP, Brasil.

${ }^{3}$ Instituto de Assistência Médica ao Servidor Público Estadual, Programa de Residência em Medicina do Trabalho. São Paulo, SP, Brasil.
\end{abstract}

Contato:

João Silvestre da Silva-Junior

E-mail:

silvajunior.js@gmail.com

\section{*In memorian}

Trabalho apresentado como tema livre no $15^{\circ}$ Congresso Nacional da Associação Nacional de Medicina do Trabalho (Anamt), em São Paulo, em 2013, com parte dos dados publicados no formato de resumo ampliado. Trabalho apresentado como pôster no $4^{\circ}$ Congresso Brasileiro de Perícia Médica Previdenciária, no Recife, em 2013, sem publicação do material.

Os autores declaram que o trabalho não foi subvencionado e que não há conflitos de interesses.
Recebido: 03/10/2013

Revisado: 27/06/2014

Aprovado: 02/07/2014

\section{Resumo}

Introdução: o Nexo Técnico Epidemiológico Previdenciário (NTEP) modificou a caracterização da etiologia ocupacional de agravo que justifica benefício previdenciário auxílio-doença no Brasil. Objetivo: descrever o perfil de requerimentos em que houve indicação de NTEP pelo sistema previdenciário e analisar fatores associados à caracterização/descaracterização do nexo pela perícia médica. Métodos: estudo retrospectivo analítico, com amostra de 822 laudos médicos periciais emitidos em São Paulo, entre 2008 e 2011. Realizada regressão logística para avaliar a associação entre a caracterização do NTEP e sexo, idade e diagnóstico incapacitante. Resultados: o perfil dos segurados foi de homens (60,6\%), na faixa etária de 30-39 anos (31,8\%), com lesão por causa externa (35,0\%). Foi descaracterizado o NTEP em 59\% das situações, a maioria devido ao relato dos trabalhadores de que a lesão não tinha ocorrido no trabalho (70,9\%). Houve associação entre a caracterização do NTEP e o diagnóstico da doença incapacitante, principalmente em relação aos distúrbios osteomusculares (OR 7,45; IC 95\% 4,88-11,38). Conclusão: o diagnóstico é um fator fortemente associado à aplicação do NTEP pela perícia médica. Há uma descaracterização frequente da espécie acidentária nos requerimentos, o que pode minimizar a justiça social ao trabalhador lesionado em decorrência do exercício do seu trabalho.

Palavras-chave: previdência social; saúde do trabalhador; laudo pericial; notificação de acidentes de trabalho; epidemiologia ocupacional.

\begin{abstract}
Background: the Technical Epidemiological Nexus of Social Security (NTEP in Portuguese) has modified the characterization of occupational injuries during evaluation for sickness benefits in Brazil. Objective: to describe the profile of sickness benefit requirements when NTEP was indicated by the social security system, and to analyze the factors associated with its characterization/mischaracterization through medical evaluation. Methods: retrospective analytical study with a sample of 822 expert medical reports issued in Sao Paulo between 2008 and 2011. A logistic regression model analysis was performed to assess the association between the characterization of NTEP and sex, age, and diagnosis. Results: the profile of the beneficiaries was as follows: males (60.6\%), aged 30-39 (31.8\%), and presenting sickness due to injuries by external causes (35.0\%). NTEP was mischaracterized in 59\% of the cases, mostly because workers reported that the injury had not occurred at work (70.9\%). There was an association between NTEP characterization and disabling diagnosis, mainly due to musculoskeletal disorders (OR 7.45; 95\%CI 4.88-11.38). Conclusion: the disabling diagnosis is a factor strongly associated with NTEP characterization by medical experts. Commonly, there is a mischaracterization of its application, which could minimize social justice for workers with occupational injury.
\end{abstract}

Keywords: social security; occupational health; expert testimony; occupational accidents registry; occupational epidemiology. 


\section{Introdução}

A Constituição Federal brasileira estabelece o acesso ao trabalho como um direito social dos cidadãos e redução de riscos ocupacionais por meio de normas de saúde, higiene e segurança (BRASIL, 1988). A prevenção de agravos relacionados ao trabalho é um importante componente nas relações trabalhistas e há prerrogativas de reparação de dano caso inexistam ações preventivas eficazes (BRASIL, 2002) ${ }^{4}$.

Outro direito social é a previdência, responsável por distribuir renda quando há incapacidade para o desempenho de atividade laborativa. No processo de avaliação do direito ao benefício previdenciário auxíliodoença, cabe ao perito médico do Instituto Nacional do Seguro Social (INSS) avaliar se o requerente incapaz apresenta agravo à saúde desencadeado ou agravado pelo trabalho (SOUZA et al., 2008).

Todos os trabalhadores com relação de trabalho regida pela Consolidação das Leis do Trabalho (CLT) têm direito à estabilidade, com manutenção do seu contrato de trabalho na empresa, pelo prazo mínimo de 12 meses após a cessação do recebimento do auxíliodoença por agravo relacionado ao trabalho (BRASIL, 1991, art. 118). Além disso, durante a vigência do afastamento deverão ser mantidas as contribuições do Fundo de Garantia do Tempo de Serviço (FGTS) (BRASIL, 1990, art. 15).

O critério legal para a caracterização da espécie acidentária do benefício - a relação entre o adoecimento incapacitante e as condições de trabalho - é determinado pela aplicação do nexo técnico previdenciário que pode ser de três tipos (BRASIL, 1999):

- Nexo técnico profissional ou do trabalho - fundamentado nas associações entre patologias e exposições ocupacionais de acordo com a profissiografia do segurado, descrito nas listas A e B do anexo II do Decreto no 3.048/99 (BRASIL, 1999);

- Nexo técnico por doença equiparada a acidente de trabalho ou nexo técnico individual - decorrente de acidentes de trabalho típicos ou de trajeto, bem como de condições especiais em que o trabalho é realizado e com ele relacionado diretamente, nos termos do $\S 2$ o do art. 20 da Lei oㅡ 8.213/91 (BRASIL, 1991);
- Nexo técnico epidemiológico previdenciário (NTEP) - aplicável quando houver significância estatística da associação entre a entidade mórbida motivadora da incapacidade e a atividade econômica da empresa na qual o segurado é vinculado. Essas relações constam na lista $\mathrm{C}$ do anexo II do Decreto no 3.048/99 (BRASIL, 1999), alterado pelo Decreto no 6.042/2007 (BRASIL, 2007).

A principal ferramenta para caracterização do nexo individual é a apresentação da Comunicação de Acidente de Trabalho (CAT) ${ }^{5}$ pelo segurado no momento da perícia médica previdenciária. Em relação aos nexos técnicos profissional e epidemiológico, a caracterização se baseia em aspectos coletivos de adoecimento e dependem de indicação do Sistema de Administração de Benefícios por Incapacidade $(\mathrm{SABI})^{6}$ do INSS.

Em qualquer uma das possibilidades de nexo técnico o perito médico pode exercer sua autonomia decisória e negar a caracterização acidentária do requerimento. No caso do NTEP, a legislação instituiu que o ônus da prova é da empresa, pois cabe a ela demonstrar não haver fatores de risco no trabalho para o agravo incapacitante em análise (BRASIL, 2007).

Entre 2006-2007, a concessão de benefícios auxílio-doença acidentários (B91) teve um aumento expressivo a partir da implantação do NTEP. Estudos demonstraram que o nexo epidemiológico influenciou quadros específicos, como respiratório (BRANCO; ILDEFONSO, 2012) e neurológico (LUNARDI et al., 2011). Acerca dos transtornos mentais, houve um aumento na ordem de $1.157 \%$ no número de concessões nesse biênio (SELIGMANN-SILVA et al., 2010). Estudo mais recente demonstrou uma diminuição persistente da concessão de auxíliodoença acidentário (B91) entre 2008-2011 (SILVA JUNIOR; FISCHER, 2014).

Considerando o NTEP um mecanismo de aplicação recente e de impacto social, este estudo tem por objetivo descrever o perfil de situações em que houve indicação de NTEP pelo sistema previdenciário e analisar os fatores associados à caracterização/descaracterização do nexo epidemiológico nas avaliações periciais de incapacidade laborativa do INSS.

\footnotetext{
4 Código Civil, art. 950: "Se da ofensa resultar defeito pelo qual o ofendido não possa exercer o seu ofício ou profissão, ou se Ihe diminua a capacidade de trabalho, a indenização, além das despesas do tratamento e lucros cessantes até ao fim da convalescença, incluirá pensão correspondente à importância do trabalho para que se inabilitou, ou da depreciação que ele sofreu.” (BRASIL, 2002)

5 Por meio da CAT, todas as empresas são obrigadas pela Lei 8.213/91 (BRASIL, 1991) a informar à Previdência Social todos os acidentes de trabalho ocorridos com seus empregados, mesmo que não haja afastamento das atividades, até o primeiro dia útil seguinte ao da ocorrência. Em caso de morte, a comunicação deve ser imediata (MINISTÉRIO DA PREVIDÊNCIA SOCIAL, 2014).

6 "O SABI (Sistema de Administração de Benefícios por Incapacidade) é um conjunto de aplicações que tem por objetivo o reconhecimento inicial do direito dos benefícios que necessitam de Perícia Médica para serem concedidos e mantidos.” (MINISTÉRIO DA PREVIDÊNCIA SOCIAL, 2009)
} 


\section{Metodologia}

Este é um estudo retrospectivo analítico, realizado com dados coletados em uma Agência da Previdência Social (APS) localizada na região central da cidade de São Paulo. A seleção da amostra foi baseada na coleta de Comunicação de Resultado de Exame e Requerimento (CRER) emitida por conclusão da análise de requerimentos de benefícios previdenciários auxílio-doença no período 2008-2011.

Foi critério de inclusão na pesquisa a presença na CRER da indicação do SABI para que a perícia médica analisasse o NTEP indicado. Os requerimentos que cumpriram tal critério tiveram os seus respectivos laudos médico-periciais acessados no sistema para montagem do banco de dados a ser analisado.

Informações referentes ao sexo, idade, diagnóstico motivador da incapacidade laborativa padronizado pela Classificação Estatística Internacional de Doenças e Problemas Relacionados com a Saúde 10 ${ }^{\underline{a}}$ versão (CID-10) (ORGANIZAÇÃO MUNDIAL DE SAÚDE, 1996) foram acessadas nos laudos médico-periciais e tabuladas. A caracterização acidentária do benefício auxílio-doença por incapacidade laborativa pela aplicação do NTEP foi considerada desfecho de interesse. Nos casos em que houve descaracterização do nexo técnico epidemiológico previdenciário também foram tabulados o motivo, conforme SABI, e a justificativa descrita no laudo pericial pelo perito médico.

O tamanho da amostra (BARTLETT; KOTRLIK; HIGGINS, 2001) foi calculado para uma estimativa confiável da proporção em população ilimitada. Considerou-se um grau de confiança de $95 \%(\alpha<0,05)$ e um erro máximo de estimativa de $5 \%$. A proporção do desfecho foi baseada nos dados dos acidentes de trabalho registrados pela Previdência Social sem emissão de CAT, que totalizaram $27 \%$ no ano de 2008 (MINISTÉRIO DA PREVIDÊNCIA SOCIAL, 2009). É sabido que os acidentes de trabalho sem CAT são aqueles que a Previdência Social reconhece como caracterizados pelo nexo profissional e, principalmente, epidemiológico. A amostragem mínima deveria ser de 302, mas foi possível o estudo de 822 laudos.

Procedeu-se com análise estatística construindose modelos de regressão logística univariada. As variáveis com $\mathrm{p}<0,20$ foram selecionadas para a regressão logística múltipla. No modelo final para o estudo da associação entre a caracterização acidentária do benefício pela aplicação do NTEP (sim/não) e as variáveis independentes - sexo, faixa etária e agravo à saúde -, considerou-se significância estatística o valor de $\mathrm{p}<0,05$. Foi utilizado o programa Epidata versão 3.1 para montagem do banco de dados. Os dados foram analisados com uso do software Epi-info ${ }^{\mathrm{TM}}$ versão 7.1.1.14.
O projeto de pesquisa que originou este estudo foi submetido ao Comitê de Ética em Pesquisa da Faculdade de Saúde Pública da Universidade de São Paulo que considerou não haver necessidade de emissão de parecer, conforme ofício 423/11.

\section{Resultados}

Foram coletados 822 laudos médico-periciais, sendo que na maioria eram segurados do sexo masculino $(60,6 \%)$ e adulto jovem na faixa etária de 20 a 39 anos $(61,0 \%)$. Os agravos mais frequentes foram: lesões, envenenamento e algumas outras consequências de causas externas (Capítulo XIX - CID10 S00-T98) $(35,0 \%)$; doenças do sistema osteomuscular e do tecido conjuntivo (Capítulo XIII - CID10 M00-M99) (30,0\%); e transtornos mentais e comportamentais (Capítulo $\mathrm{V}$ - CID10 F00-F99) (17,8\%) (Tabela 1) (ORGANIZAÇÃO MUNDIAL DA SAÚDE, 1996).

O NTEP foi descaracterizado em $59,0 \%$ das situações na qual o sistema indicou relação entre CNAE do empregador e CID-10 incapacitante. Dos grupamentos diagnósticos mais frequentes, lesões, envenenamento e algumas outras consequências de causas externas $(17,4 \%)$, doenças do aparelho circulatório (Capítulo IX - CID10 I00-I99) (ORGANIZAÇÃO MUNDIAL DA SAÚDE, 1996) (40,6\%) e transtornos mentais e comportamentais $(44,5 \%)$ foram os agravos menos caracterizados pelos peritos como acidentários (Tabela 1).

A principal justificativa descrita pelos peritos médicos previdenciários para descaracterizar o NTEP foi que o segurado periciado relatava que a lesão não ocorreu no trabalho $(70,9 \%)$ (Tabela 2). Neste grupo, a principal descrição presente no laudo médico-pericial era de "acidente não aconteceu no local ou horário de trabalho" (60,8\%). Também se destacam relatos de "doença não relacionada ao trabalho" (27,9\%), "não trouxe CAT" ou "não sabe informar a causa" $(8,4 \%)$, e mesmo "acidente de trajeto" $(2,0 \%)$.

Em 25,4\% das negativas à aplicação do NTEP, a decisão pericial se baseou em considerar incompatível a queixa como um quadro relacionado ao trabalho (Tabela 2). A justificativa de que os quadros eram de doença autoimune, crônica, degenerativa, endêmica, idiopática, orgânica, prévia ao trabalho, motivada por fatores pessoais, gravidez ou sequela de doença de base somaram $51,2 \%$ de tais descaracterizações. Em 46,3\% dos laudos desse grupo, as justificativas descritas foram "doença não ocupacional", "não se aplica" ou "não se enquadra".

A descaracterização do NTEP por falta de evidências de exposição ocupacional a fatores de risco para o agravo incapacitante foi justificativa descrita em 2,7\% dos laudos periciais (Tabela 2). Todavia, descrições 
Tabela 1 Distribuição das informações descritas nos laudos de avaliações periciais de incapacidade laborativa de uma Agência da Previdência Social do INSS conforme sexo, faixa etária, diagnóstico do agravo incapacitante e a caracterização do nexo técnico epidemiológico previdenciário (NTEP), São Paulo, 2008-2011

\begin{tabular}{|c|c|c|c|c|c|c|}
\hline & $N T E P \operatorname{sim}(N=337)$ & $\%$ & NTEP não $(N=485)$ & $\%$ & Total $(N=822)$ & $\%$ \\
\hline \multicolumn{7}{|l|}{ Sexo } \\
\hline Masculino & 178 & 35,7 & 320 & 64,3 & 498 & 60,6 \\
\hline Feminino & 159 & 49,1 & 165 & 50,9 & 324 & 39,4 \\
\hline \multicolumn{7}{|l|}{ Faixa etária } \\
\hline $0-19$ & 2 & 16,7 & 10 & 83,3 & 12 & 1,5 \\
\hline $20-29$ & 86 & 35,8 & 154 & 64,2 & 240 & 29,2 \\
\hline $30-39$ & 118 & 45,2 & 143 & 54,8 & 261 & 31,8 \\
\hline $40-49$ & 81 & 42,4 & 110 & 57,6 & 191 & 23,2 \\
\hline $50-59$ & 44 & 43,1 & 58 & 56,9 & 102 & 12,4 \\
\hline$>60$ & 7 & 43,7 & 9 & 56,3 & 16 & 1,9 \\
\hline \multicolumn{7}{|l|}{ Agravo à saúde } \\
\hline Lesões por causas externas & 50 & 17,4 & 238 & 82,6 & 288 & 35,0 \\
\hline Doenças do sistema osteomuscular & 153 & 61,9 & 94 & 38,1 & 247 & 30,0 \\
\hline Transtornos mentais e comportamentais & 65 & 44,5 & 81 & 55,5 & 146 & 17,8 \\
\hline Doenças do aparelho circulatório & 26 & 40,6 & 38 & 59,4 & 64 & 7,8 \\
\hline Doenças do aparelho digestivo & 30 & 58,8 & 21 & 41,2 & 51 & 6,2 \\
\hline Doenças do sistema nervoso & 10 & 55,6 & 8 & 44,4 & 18 & 2,2 \\
\hline Outros & 4 & 50,0 & 4 & 50,0 & 8 & 1,0 \\
\hline
\end{tabular}

Tabela 2 Justificativas para a descaracterização do nexo técnico epidemiológico previdenciário (NTEP) indicadas nos laudos médico-periciais de requerimentos de auxílio-doença coletados em uma Agência da Previdência Social do INSS, São Paulo, 2008-2011

\begin{tabular}{lcc}
\hline \multicolumn{1}{c}{ Justificativa } & $N$ & $\%$ \\
\hline O segurado informa que a lesão não ocorreu no trabalho & 344 & 70,9 \\
A queixa descrita não é compatível com lesão ocupacional & 123 & 25,4 \\
Não há evidência/indícios de exposição a riscos ocupacionais & 13 & 2,7 \\
Tempo entre o início da função/trabalho e o início da doença (DID) é insuficiente para gerar a moléstia de origem & 5 & 1,0 \\
ocupacional & 485 \\
Total & 100,0 \\
\hline
\end{tabular}

de vistoria em local de trabalho ou de análise de documentação técnica emitida pelo vínculo empregatício do segurado requerente eram inexistentes.

Frente aos resultados da regressão logística univariada, todas as variáveis foram selecionadas para o modelo múltiplo (Tabela 3). Na análise múltipla, a variável agravo de saúde esteve associada ao desfecho. Os diagnósticos de quadros osteomusculares, doenças gastroenterológicas e doenças do sistema nervoso apresentaram maior Odds Ratio (OR) da perícia estabelecer NTEP nos requerimentos de auxílio-doença. As variáveis sexo e faixa etária ajustaram o modelo, mas não foram estatisticamente significantes.

\section{Discussão}

A indicação do nexo técnico epidemiológico legalmente definido é informada ao perito médico previdenciário pelo SABI. Conforme os resultados, o perfil de requerente passível de fazer jus a um auxílio-doença de espécie acidentária por aplicação do NTEP foi majoritariamente do sexo masculino, de faixa etária inferior a 39 anos e cujo principal motivo de incapacidade foram quadros de lesão por causas externas. Entretanto, mais da metade das situações possíveis de confirmação do NTEP foram descaracterizadas. 
Tabela 3 Análise de regressão logística univariada e múltipla acerca da associação entre caracterização do nexo técnico epidemiológico previdenciário (NTEP) e as variáveis independentes sexo, faixa etária e diagnóstico do agravo incapacitante de laudos médico-periciais de requerimentos de auxíliodoença de uma Agência da Previdência Social do INSS, São Paulo, 2008-2011 (N = 822)

\begin{tabular}{|c|c|c|c|c|}
\hline & OR Univariada (IC 95\%) & $p$ & OR Múltipla (IC 95\%) & $p$ \\
\hline \multicolumn{5}{|l|}{ Sexo } \\
\hline Masculino & 1 & & 1 & \\
\hline Feminino & $1,72(1,29-2,28)$ & 0,001 & $1,21(0,87-1,66)$ & 0,253 \\
\hline \multicolumn{5}{|l|}{ Faixa etária } \\
\hline $0-19$ & 1 & & 1 & \\
\hline $20-29$ & $2,79(0,60-13,04)$ & 0,192 & $1,27(0,26-6,21)$ & 0,767 \\
\hline $30-39$ & $4,13(0,89-19,20)$ & 0,071 & $1,31(0,27-6,41)$ & 0,742 \\
\hline $40-49$ & $3,68(0,79-17,26)$ & 0,098 & $1,11(0,22-5,52)$ & 0,895 \\
\hline $50-59$ & $3,79(0,79-18,19)$ & 0,096 & $1,06(0,21-5,40)$ & 0,946 \\
\hline$>60$ & $3,89(0,64-23,79)$ & 0,141 & $1,19(0,18-7,88)$ & 0,859 \\
\hline \multicolumn{5}{|l|}{ Agravo à saúde } \\
\hline Lesões por causas externas & 1 & & 1 & \\
\hline Doenças do sistema osteomuscular & $7,75(5,20-11,54)$ & $<0,001$ & $7,45(4,88-11,38)$ & $<0,001$ \\
\hline Transtornos mentais e comportamentais & $3,82(2,44-5,97)$ & $<0,001$ & $3,56(2,22-5,69)$ & $<0,001$ \\
\hline Doenças do aparelho circulatório & $3,26(1,82-5,84)$ & $<0,001$ & $3,21(1,73-5,95)$ & $<0,001$ \\
\hline Doenças do aparelho digestivo & $6,80(3,60-12,84)$ & $<0,001$ & $6,89(3,62-13,10)$ & $<0,001$ \\
\hline Doenças do sistema nervoso & $5,95(2,24-15,83)$ & $<0,001$ & $5,74(2,10-15,70)$ & 0,001 \\
\hline Outros & $4,76(1,15-19,67)$ & 0,031 & $4,69(1,12-19,60)$ & 0,034 \\
\hline
\end{tabular}

OR = Odds Ratio; IC 95\% = Intervalo de confiança de 95\%

A descaracterização equilibrou a frequência entre os sexos, aumentou a idade média e promoveu a ascensão dos distúrbios osteomusculares como principal agravo motivador da incapacidade acidentária. A confirmação do NTEP pela perícia médica previdenciária esteve associada ao diagnóstico do agravo que foi considerado como motivador da incapacidade laborativa nesse grupo, conforme análises estatísticas. Em contrapartida, não houve associação significante do desfecho com as variáveis sexo e faixa etária dos beneficiários.

O perfil da amostragem é compatível com estudo ecológico no estado de Rondônia, o qual identificou maior prevalência de beneficiários de auxílio-doença como sendo do sexo masculino (JAKOBI et al., 2013). Os três principais grupamentos de agravos classificados como os mais frequentes motivadores de concessão do benefício auxílio-doença entre os requerentes da amostra do estudo aqui apresentado são compatíveis com dados relativos ao período entre 2008 e 2011 no país - lesões por causas externas, distúrbios osteomusculares e transtornos mentais (SILVA JUNIOR; FISCHER, 2014).

O recorte do perfil dos beneficiários de auxíliodoença acidentário desta pesquisa diverge de estudos regionais e nacionais que indicam as lesões por causas externas como o principal motivo de concessão dessa espécie de benefício. Em geral, os distúrbios osteomusculares são a segunda causa mais frequente (ALMEIDA; BARBOSA-BRANCO, 2011; JAKOBI et al., 2013; SILVA JUNIOR; FISCHER, 2014). Sobre a idade dos requerentes, o resultado vai ao encontro de conclusões que indicam que o envelhecimento do trabalhador diminui a frequência de lesões por causas externas relacionadas ao trabalho (ALMEIDA; BARBOSA-BRANCO, 2011). Portanto, pode-se considerar que ao haver um menor impacto desses agravos nos motivos de concessão dessa espécie de benefício pode haver um aumento da idade média dos beneficiários.

Apesar de autores indicarem que quadros crônicos envolvem uma maior dificuldade para estabelecer o nexo causal (SOUZA et al., 2008), as morbidades osteomusculares, mentais, gastrointestinais, cardiovasculares e neurológicas estiveram fortemente associadas à concessão de auxílio-doença acidentário nos nossos resultados. As doenças crônicas não transmissíveis são importantes fontes de carga de adoecimento e morte no Brasil (SCHMIDT et al., 2011), e ao longo dos anos os trabalhadores vão se 
tornando mais susceptíveis a tais agravos, inclusive por exposição a fatores de risco em ambientes de trabalho.

A ausência da associação estatística com sexo e idade pode ser explicada, principalmente, pela descaracterização das relações epidemiológicas de CNAE e o grupamento CID-10 S00-T98. Esses agravos afetam essencialmente trabalhadores do sexo masculino (JAKOBI et al., 2013) e jovens (ALMEIDA; BARBOSABRANCO, 2011). Portanto, a taxa de negativa do NTEP superior a $80 \%$ pode ter influenciado na perda da significância estatística das variáveis sexo e idade no modelo final, por serem variáveis que se sobrepõem ao diagnóstico do agravo incapacitante.

O presente estudo apresenta limitações, como a coleta ter sido restrita a uma unidade da Previdência Social em uma cidade urbana com seleção não aleatória da amostragem, o que inviabiliza a generalização dos achados. A falta de dados relativos aos peritos médicos previdenciários responsáveis pelas avaliações é um viés, pois a formação complementar em Medicina do Trabalho ou Legislação Previdenciária e o tempo de atividade na função podem influenciar nos critérios individuais para caracterização/descaracterização do NTEP. A ausência de outras variáveis de interesse prejudica o poder de explicação das análises de fatores associados ao desfecho.

Apesar das limitações, os autores acreditam que este estudo pode trazer contribuição relevante, pois há insuficiência na literatura científica brasileira sobre o processo previdenciário de caracterização da espécie acidentária nos requerimentos de benefício auxílio-doença.

Estudo brasileiro sobre dados de 2008 considerou baixas as taxas de prevalência de benefícios por acidente de trabalho quando comparadas a países desenvolvidos. Uma das justificativas seria a questão da subnotificação por parte dos empregadores, tais como a não emissão da CAT (ALMEIDA; BARBOSABRANCO, 2011). A introdução do NTEP é considerada uma possível solução ao problema apresentado, pois levou ao fim a vinculação da concessão de benefícios acidentários à entrega da CAT (CHAGAS; SALIM; SERVO, 2011).

Cabe indicar que mesmo após a institucionalização do NTEP está mantida a obrigatoriedade de comunicar o acidente do trabalho à Previdência Social até o primeiro dia útil seguinte ao da ocorrência (BRASIL, 1991, art. 22). Entretanto, não cabe relacionar a presença ou ausência da CAT às análises de nexo técnico epidemiológico previdenciário, como foram descritos em laudos periciais analisados neste estudo.

O NTEP traz a possibilidade de se utilizarem critérios da Epidemiologia Ocupacional na análise das relações entre adoecimento incapacitante e trabalho. Essa ferramenta trouxe mudança no padrão das concessões de benefício, promovendo um novo perfil epidemiológico com diversificação dos agravos à saúde considerados ocupacionais (LUNARDI et al., 2011; BRANCO; ILDEFONSO, 2012). Essa abordagem pode facilitar o exercício da atividade médico-pericial, haja vista que nem todos os servidores possuem formação em Medicina do Trabalho. Todavia, onde a relação causal é discutível, cabe um aprofundamento da análise, com decisão fundamentada, mesmo nas situações de descaracterização do nexo. Dessa forma deve-se prezar para que a ferramenta não entre em descrédito social (SILVA-JUNIOR; ALMEIDA; MORRONE, 2012).

Uma das principais modificações implantadas pelo nexo epidemiológico foi determinar que cabe à empresa provar que não foi a responsável pela doença incapacitante (TECHY; SIENA; HELFENSTEIN JUNIOR, 2009). Essa inversão do ônus da prova abre um espaço para que as empresas emitam documentação de contestação em situações legalmente estabelecidas como NTEP a serem analisadas na primeira avaliação pericial do requerimento. Dessa forma, a perícia pode se embasar em elementos técnicos formais nas situações que ensejam descaracterização do nexo. Assim, mantém-se o ônus da prova a cargo do empregador e se diminui a importância de informações verbais, como nas situações nas quais o requerente nega que a lesão tenha ocorrido no trabalho, mais susceptíveis à influência de pressões.

A instituição previdenciária deve investir em treinamentos periódicos para padronizar os critérios de análise e minimizar vieses relativos a perfil técnico, administrativo e ideológico-político. Também é recomendável a realização de monitoramento periódico da qualidade técnica das atividades periciais, a fim de corrigir inconsistências e encaminhar para cursos de atualização os profissionais insuficientes.

Como a aplicação do NTEP possibilita a interposição de contestação pelas partes, e tais recursos devem ser analisados pela perícia médica, levanta-se a hipótese de que as situações na qual caberia a aplicação do NTEP têm sido descaracterizadas de forma arbitrária para minimizar futura carga de trabalho aos peritos do INSS. Autores descrevem que essa categoria de servidores pode estar desmotivada pela falta de oportunidades de contribuir com o planejamento de uma política efetivamente previdenciária (PINTO JÚNIOR; BRAGA; ROSELLI-CRUZ, 2012).

$\mathrm{Na}$ análise da etiologia ocupacional de um adoecimento, três pontos devem ser levados em consideração: evidência da doença, evidência da exposição e evidência da relação causal. Por vezes, o estabelecimento do nexo causal é uma decisão política, pois afeta muitas partes interessadas, com consequências sociais múltiplas (VERBEEK, 2012). 
A aplicação do NTEP pode ser melhorada com a realização de anamnese focada em descrição da história ocupacional, o estímulo à avaliação do posto de trabalho e a padronização da análise do nexo por meio de diretrizes médico-periciais em doenças ocupacionais (CONSELHO FEDERAL DE MEDICINA, 1998). Algumas documentações podem aprofundar e auxiliar essa discussão da relação entre doença e trabalho, como: Programa de Prevenção de Riscos Ambientais (PPRA), Programa de Gerenciamento de Riscos (PGR), Programa de Controle do Meio Ambiente de Trabalho (PCMAT), Programa de Controle Médico de Saúde Ocupacional (PCMSO), Laudo Técnico de Condições Ambientais de Trabalho (LTCAT), Perfil Profissiográfico Previdenciário (PPP), Comunicação de Acidente de Trabalho (CAT), relatórios e documentos médicos ocupacionais (INSTITUTO NACIONAL DO SEGURO SOCIAL, 2008).

Autores consideram que a introdução do NTEP minimizou a subnotificação de acidentes de trabalho no setor formal, nos casos de longo afastamento por doença (CHAGAS; SALIM; SERVO, 2011). Todavia, estudo recente (SILVA JUNIOR; FISCHER, 2014) demonstra uma queda persistente na configuração acidentária dos benefícios previdenciários auxíliodoença no país. Os motivos dessa nova mudança nos padrões previdenciários devem motivar outras pesquisas e discussões sobre essa temática.

Este estudo apresenta que o diagnóstico motivador da incapacidade é um fator fortemente associado à aplicação do NTEP pela perícia médica previdenciária. Também indicou que há uma descaracterização frequente da espécie acidentária em requerimentos em que o diagnóstico incapacitante é uma lesão por causa externa. A abordagem epidemiológica das informações previdenciárias é importante na construção de políticas públicas em Saúde do Trabalhador para promoção da saúde, prevenção de adoecimento e reabilitação profissional (PINTO JÚNIOR; BRAGA; ROSELLICRUZ, 2012; JAKOBI et al., 2013). Discutir a correta aplicação do NTEP é essencial para garantir justiça social a cada trabalhador lesionado em decorrência do exercício do seu trabalho e impedido de ser produtivo para a sociedade em decorrência da incapacidade de que foi acometido.

\section{Contribuições de autoria}

Silva-Junior, J. S.: participou da concepção do projeto, coleta e análise dos dados, e da redação do artigo. Almeida, F. S. S.: participou da análise dos dados, redação do artigo e revisão crítica do conteúdo intelectual. Santiago, M. P.: participou da redação do artigo e revisão crítica do conteúdo intelectual. Morrone, L. C.: participou da aprovação final da versão a ser publicada.

\section{Agradecimentos}

Os autores agradecem à Diretoria de Saúde do Trabalhador do Instituto Nacional do Seguro Social (INSS) pela autorização para realização do estudo.

\section{Referências}

ALMEIDA, P. C. A.; BARBOSA-BRANCO, A. Acidentes de trabalho no Brasil: prevalência, duração e despesa previdenciária dos auxílios-doença. Revista Brasileira de Saúde Ocupacional, v. 36, n. 124, p. 195-207, 2011. http://dx.doi.org/10.1590/S0303-76572011000200003.

BARTLETT, J. E.; KOTRLIK, J. W.; HIGGINS, C. C. Organizational research: determining appropriate sample size in survey research. Information Technology, Learning and Performance Journal, v. 19, n. 1, p. 43-50, 2001.

BRANCO, A. B.; ILDEFONSO, S. A. Prevalência e duração dos benefícios auxílio-doença decorrentes de asma no Brasil em 2008. Jornal Brasileiro de Pneumologia, v. 38, n. 5, p. 550-558, 2012. http:// dx.doi.org/10.1590/S1806-37132012000500003. PMid:23147046
BRASIL. Constituição da República Federativa do Brasil de 1988. Diário Oficial [da] República Federativa do Brasil, Brasília, DF, 05 out. 1988. Disponível em: <http://www.planalto.gov.br/ccivil_03/ constituicao/ConstituicaoCompilado.htm > . Acesso em: 28 out. 2014 .

BRASIL. Decreto nํ 8.036, de 11 de maio de 1990. Dispõe sobre o Fundo de Garantia do Tempo de Serviço, e dá outras providências. Diário Oficial [da] República Federativa do Brasil, Brasília, DF, 11 maio 1990. Disponível em: <http://www.planalto.gov.br/ ccivil_03/leis/18036consol.htm>. Acesso em: 28 out. 2014.

BRASIL. Lei nํ 8.213, de 24 de julho de 1991. Dispõe sobre os Planos de Benefícios da Previdência Social e dá outras providências. Diário Oficial [da] República 
Federativa do Brasil, Brasília, DF, 14 ago. 1991. Disponível em: < http://www.planalto.gov.br/ccivil_03/ leis/l8213cons.htm>. Acesso em: 28 out. 2014.

BRASIL. Decreto no 3.048, de 06 de maio de 1999. Aprova o Regulamento da Previdência Social, e dá outras providências. Diário Oficial [da] República Federativa do Brasil, Brasília, DF, 07 maio 1999. Disponível em: <http://www.planalto.gov.br/ccivil_03/ decreto/d3048.htm > . Acesso em: 28 out. 2014.

BRASIL. Lei no 10.406, de 10 de janeiro de 2002. Institui o Código Civil. Diário Oficial [da] República Federativa do Brasil, Brasília, DF, 11 jan. 2002. Disponível em: < http://www.planalto.gov.br/ccivil_03/ leis/2002/L10406.htm\#art2045 >. Acesso em: 28 out. 2014.

BRASIL. Decreto nํㅡ 6.042, de 12 de fevereiro de 2007. Altera o Regulamento da Previdência Social, aprovado pelo Decreto $n^{-} \mathbf{3}$ 3.048, de 6 de maio de 1999, disciplina a aplicação, acompanhamento e avaliação do Fator Acidentário de Prevenção - FAP e do Nexo Técnico Epidemiológico, e dá outras providências. Diário Oficial [da] República Federativa do Brasil, Brasília, DF, 13 fev. 2007. Disponível em < http://www.planalto. gov.br/ccivil_03/_ato2007-2010/2007/decreto/d6042. htm >. Acesso em 28 out. 2014.

CHAGAS, A. M. R.; SALIM, C. A.; SERVO, L. M. S. (Org.). Saúde e segurança no trabalho no Brasil: aspectos institucionais, sistemas de informação e indicadores. Brasília: IPEA, 2011. Disponível em: <http://desafios2.ipea.gov.br/agencia/images/ stories/PDFs/livros/livros/livro_saudenotrabalho. pdf\# page=78>. Acesso em: $0 \overline{1}$ out. 2013 .

CONSELHO FEDERAL DE MEDICINA. Resolução $n^{\circ}$ 1.488, de 06 de março de 1998. Dispõe de normas específicas para médicos que atendam o trabalhador. Diário Oficial [da] República Federativa do Brasil, Brasília, DF, 06 mar. 1998. Seção 1, p. 150.

INSTITUTO NACIONAL DO SEGURO SOCIAL. Instrução Normativa no 31, de 10 de setembro de 2008. Dispõe sobre procedimentos e rotinas referentes ao Nexo Técnico Previdenciário, e dá outras providências. Diário Oficial [da] República Federativa do Brasil, Brasília, DF, 11 set. 2008. Seção 1, p. 58.

JAKOBI, H. R. et al. Incapacidade para o trabalho: análise dos benefícios auxílio-doença concedidos no estado de Rondônia. Ciencia \& Saude Coletiva, v. 18, n. 11, p. 3157-3168, 2013. http://dx.doi.org/10.1590/ S1413-81232013001100006. PMid:24196881

LUNARDI, M. S. et al. Epilepsia e acidentes de trabalho no Brasil: um estudo das estatísticas nacionais. Arquivos de Neuro-Psiquiatria, v. 69, n. 2B, p. 332-335, 2011. http://dx.doi.org/10.1590/S0004282X2011000300013. PMid:21625761

MINISTÉRIO DA PREVIDÊNCIA SOCIAL. Anuário Estatístico da Previdência Social: 2008. Brasília: MPS, 2009.
. Sistema de Administração de Benefícios por Incapacidade - SABI. 2009. Disponível em: < http:// www3.dataprev.gov.br/sabi/apresentacao.htm $>$. Acesso em: 29 out. 2014.

. Cadastro da Comunicação de Acidente de Trabalho - CAT. 2014. Disponível em: < http://agencia. previdencia.gov.br/e-aps/servico/327>. Acesso em: 29 out. 2014.

ORGANIZAÇÃO MUNDIAL DA SAÚDE. Classificação Estatística Internacional de Doenças e Problemas Relacionados à Saúde, 10a Revisão: CID-10. Tradução do Centro Colaborador da OMS para a Classificação de Doenças em Português. 3. ed. São Paulo: EDUSP, 1996.

PINTO JÚNIOR, A. G.; BRAGA, A. M. C. B.; ROSELLICRUZ, A. Evolução da saúde do trabalhador na perícia médica previdenciária no Brasil. Ciência \& Saúde Coletiva, v. 17, n. 10, p. 2841-2849, 2012. http://dx.doi.org/10.1590/S1413-81232012001000031. PMid:23099769

SCHMIDT, M. I. et al. Doenças crônicas não transmissíveis no Brasil: carga e desafios atuais. Lancet, v. 377, n. 9781, p. 1949-1961, 2011. http:// dx.doi.org/10.1016/S0140-6736(11)60135-9. PMid:21561658

SELIGMANN-SILVA, E. et al. O mundo contemporâneo do trabalho e a saúde mental do trabalhador. Revista Brasileira de Saúde Ocupacional, v. 35, n. 122, p. 187-191, 2010. http://dx.doi. org/10.1590/S0303-76572010000200002.

SILVA-JUNIOR, J. S.; ALMEIDA, F. S. S.; MORRONE, L. C. Discussão dos impactos do nexo técnico epidemiológico previdenciário. Revista Brasileira de Medicina do Trabalho, São Paulo, n. 10, v. 2, p. 72-79, 2012.

SILVA JUNIOR, J. S.; FISCHER, F. M. Adoecimento mental incapacitante: benefícios previdenciários no Brasil entre 2008-2011. Revista de Saúde Pública, v. 48, n. 1, p. 186-190, 2014. http://dx.doi.org/10.1590/ S0034-8910.2014048004802. PMid:24789650

SOUZA, N. S. S. et al. Doenças do trabalho e benefícios previdenciários relacionados à saúde, Bahia, 2000. Revista de Saúde Pública, v. 42, n. 4, p. 630-638, 2008. http://dx.doi.org/10.1590/S003489102008000400008. PMid:18709240

TECHY, A.; SIENA, C.; HELFENSTEIN JUNIOR, M. O exercício legal da medicina em LER/DORT. Revista Brasileira de Reumatologia, v. 49, n. 4, p. 473-479, 2009. http://dx.doi.org/10.1590/S048250042009000400014 .

VERBEEK, J. When work is related to disease, what establishes evidence for a causal relation? Safety and Health at Work, v. 3, n. 2, p. 110-116, 2012. http://dx.doi.org/10.5491/SHAW.2012.3.2.110. PMid:22993715 